\title{
Development of a Human Error Hazard Identification Method for Introducing Smart Mobiles to Nuclear Power Plants
}

\author{
Yong Hee Lee ${ }^{1}$, Jong Hun Yun ${ }^{2}$, Yonghee Lee ${ }^{1}$ \\ ${ }^{1}$ I\&C and Human Factors Division, Korea Atomic Energy Research Institute (KAERI), Daejeon, 305-353 \\ ${ }^{2}$ Administration Department, Korea Institute of Construction Technology (KICT), Goyang-Si, Gyeonggi-Do, 411-712
}

\begin{abstract}
Objective: The aim of this study is to develop an analysis method to extract plausible types of errors when using a smart mobile in nuclear power plants. Background: Smart mobiles such as a smart-phone and a tablet computer(smart-pad) are to be introduced to the various industries. Nuclear power plant like APR1400 already adopted many up-to-date digital devices within its main control room. With this trend, various types of smart mobiles will be inevitably introduced to the nuclear field in the near future. However nuclear power plants(NPPs) should be managed considering a big risk as a result of the trend not only economically but also socially compared to the other industrial systems. It is formally required to make sure to reasonably prevent the all hazards due to the introduction of new technologies and devices before the application to the specific tasks in nuclear power plants. Method: We define interaction segments(IS) as a main architect of interaction description, and enumerate all plausible error segments(ES) for a part of design evaluation of digital devices. Results: We identify various types of interaction errors which are coped with reasonably by interaction design using smart mobiles. Conclusion: According to the application result of the proposed method, we conclude that the proposed method can be utilized to specify the requirements to the human error hazards in digital devices, and to conduct a human factors review during the design of digital devices. Application: The proposed method can be applied to predict the human errors of the tasks related to the digital devices; therefore we can ensure the safety to apply the digital devices to be introduced to NPPs.
\end{abstract}

Keywords: Error segment, Human error, Nuclear power plant, Smart mobile

\section{Smart Mobile as a Technical Challenge}

통신 기기의 발전으로 스마트모바일은 이미 의료, 금융 등 다양한 분야에서 활용되고 있다. 단순한 일정관리, 확인 등 을 위해 휴대용 디지털 기기를 사용했던 것과는 달리 스마 트폰과 스마트패드를 적용한 경우 현장에서 수작업으로 이 루어지던 업무를 특수한 목적의 전용 앱(application)을 통 해 원거리 조종, 간편한 상황 확인 및 실행이 가능하다. 그
덕분에 불필요한 업무와 동선이 줄어드는 등의 여러 장점을 가지고 있지만, 현장 업무 방식의 근본적인 변화는 예상하지 못하는 위험을 내포할 수 있어서 인간공학에 새로운 과제를 요구하고 있다(Yun et al., 2011).

최신 디지털 기술은 충분한 경험이 매우 부족하여 불확실 성으로 예기치 않은 현상이 발생할 위험(risk)을 내포하고 있다. 자동화에 따른 out-of-the-loop, 유지보수의 어려움, 예상치 못한 결함, 고장에 대한 대처 능력의 부족, 전자파 간 섭(electromagnetic interference, EMI) 등 다양한 기술적

Corresponding Author: Jong Hun Yun. Administration Department, Korea Institute of Construction Technology (KICT), Goyang-Si, Gyeonggi-Do, 411-712. Mobile: 010-6811-7941, E-mail: jhyun@kict.re.kr

Copyright@2012 by Ergonomics Society of Korea(pISSN:1229-1684 eISSN:2093-8462). All right reserved. 
문제점이 제기되고 있다. 인간공학 측면에서는 자동화나 무 선통신 기반의 원거리 작업이 추가적인 부담요인이며, 그로 인하여 새로운 형태의 인적오류가 발생할 가능성을 배제할 수 없는 상황이다. 원자력발전소(이하 원전) 와 같이 대형의 복합 시스템에서는 최신 디지털 기기의 도입으로 인한 불확 실성을 완전히 배제하기가 어렵다. 불확실성에 대처하지 못 할 경우에 직면하는 위험 수준이 경제적으로나 사회적으로 현저히 크기 때문에, 디지털 기기를 원전에 도입하는데 있 어서 설계의 인적오류 분석이 중요한 기술적 과제가 되고 있다(Lee, 2011).

여러 문제 제기에도 불구하고 스마트모바일은 이미 다양 한 분야에서 적용하여 사용하고 있고, 작업의 편의성은 물론 효율성도 개선할 수 있을 것으로 기대되므로, 원전에서도 업 무용으로 충분히 활용할 수 있다는 기대감이 보편화되고 있 다. 따라서, 스마트모바일과 같은 최신 기기의 원전 적용을 위해 인적오류 위험성을 사전에 분석할 수 있는 기법이 시급 한 실정이다. 특히 디지털 설계 측면에서 사후 평가가 아니 라 설계과정과 유기적으로 결합된 기법이 필요하다. 본 논문 에서는 디지털 기기의 원전 도입에 따른 인적오류 위험성을 분석하여 설계를 지원하는 방안으로, 스마트모바일을 원전에 적용할 경우에 발생 가능한 인적오류 위험성을 검출하는 기 법을 제시하고자 한다.

\section{Researches on Digital Devices in Nuclear Power Plants(NPPs)}

원전에는 다양한 디지털 기기들이 도입되어 있으며, 일본, 캐나다, 프랑스, 중국 등에서 Figure 1 과 같이 디지털 기반 의 주제어실 (main control room, MCR)을 채택하고 있다. 우리나라도 수출에 성공한 APR1400 원전에 디지털 MCR 을 개발하여 도입하였다. 원전은 최신 기술의 도입에 보수적 이지만, 산업의 동향으로 보아 스마트모바일 또한 멀지 않은 미래에 대폭 도입될 것이 분명하다.

원전에서도 Figure 2와 같이 신기술로서 스마트모바일의 적용성을 높이기 위하여 다양한 노력이 이루어지고 있다. $\mathrm{OECD}$ 국제공동연구인 할덴(Halden)에서는 $\mathrm{MCR}$ 운전원과 현장 운전원간에 스마트모바일을 통하여 기기의 위치 및 조 작상태에 대한 의사소통 및 정보전달에 AR/VR (augmented reality/virtual reality)을 이용하는 등 다양한 응용 기술을 개발하고 있다. 원전에서 무선 기술의 도입은 $\mathrm{EMI}$ 등 전자 공학적 장벽이 남았으나, 인간공학 측면에서는 $\mathrm{MCR}$ 뿐만 아니라 원전 현장에서 수행되는 직무에 상당한 변화를 일으 킬 것으로 기대된다(Yun et al., 2011).

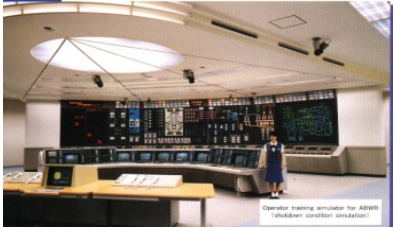

(a) Japan

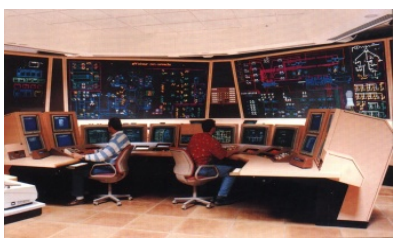

(c) France

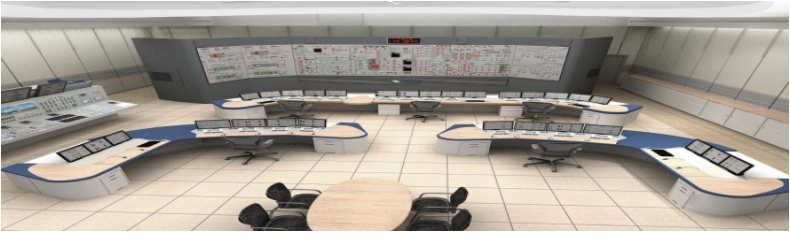

(e) Korea

Figure 1. Various Digital MCRs for NPPs

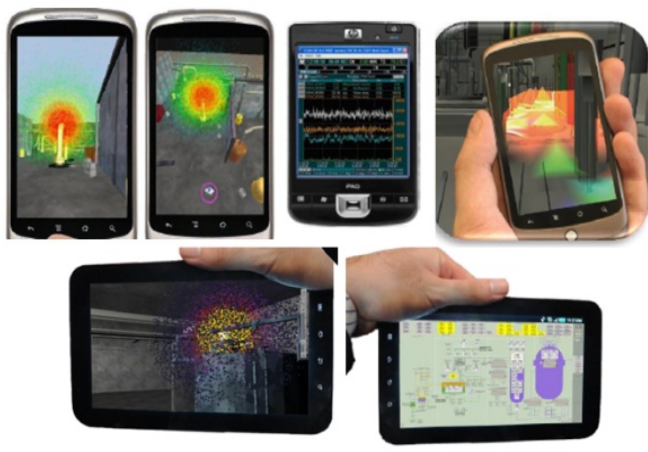

Figure 2. Researches related to smart mobiles in NPPs

원전에서 스마트모바일의 도입으로 개선할 수 있는 직무 는 Figure 3 과 같이 매우 다양하며, 기본적으로 심리적 부담 이 불가피한 현장 직무 전반에 신속히 도입되기를 기대하고 있다. 스마트모바일을 도입하게 되면, 예를 들어, 정비 및 시 험 대상의 위치 및 상세 정보, 작업 공간의 방사능 정보, 작 업의 상세 내역 및 절차 정보와 같은 직무와 관련한 의사소 통이 변화하게 된다. 특히 음성 및 문자를 넘어 화상으로 $\mathrm{MCR}$ 과 직접 통신함으로써 원전에서 중시되는 정보교환의 정확성을 효율적으로 달성하는데 이점을 가질 수 있다. 원전 현장의 소음으로 인한 의사소통 부담을 해결하고, 유지보수 
를 위해 현장에서 필요한 상세 정보와 수행 업무절차에 대한 보조자 역할을 기대할 수 있으며, 또한, 직무 수행 후 별도로 수행하는 문서화의 번거로움을 해결할 수도 있다. 그 밖에도 시험 및 정비의 통합 일정관리, 교대 시 인수인계 등에서 현 저히 개선된 작업 편의성 및 효율성을 제공하여 기술적 혁신 을 달성할 수 있을 것으로 기대된다.

일반적으로 원전의 모든 설계는 인간신뢰도분석(human reliability analysis, HRA) 또는 인간공학적 설계업무(human factors engineering program plans, HFEPP)를 통해 공 식적으로 인적오류 방지 여부가 검증되어야 한다. 그러나 정 량적 확률이나 사용자 모형으로 인적오류를 평가하기에는 한계가 있고(Lee, 2002), 또한 설계검증(validation and verification, $\mathrm{V} \& \mathrm{~V}$ ) 에서 기기나 설계에 포함된 낮은 확률의 인적오류 위험성을 경험이나 실험으로 검출하거나 확증하기 는 불가능하다.

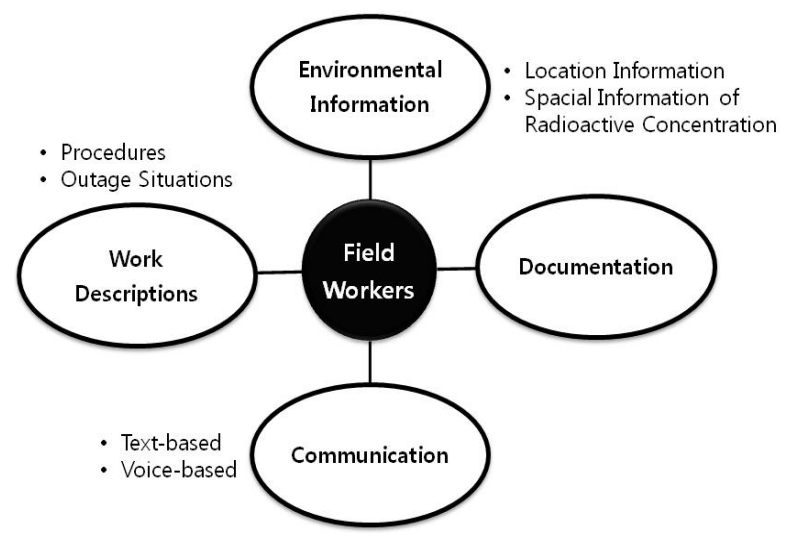

Figure 3. Expected smart mobile utilization in NPPs

기기와 사용자의 상호작용을 표현하는 기본 단위로 기능, 영향요소, 변화된 기능, 효과 등을 종합한 것이다. 단위 상호 작용이 직무상 인적오류의 일부가 되는 경우, 이를 오류절편 (error segment, ES)으로 정의한 바 있다(Lee et al., 2003). 오류절편은 Figure 4에서 보는 바와 같이 기기 고유의 설계 특성 및 기능 관련 요소는 기기의 오류절편(error segment machine, ESM)이라고 하였으며, $\mathrm{MMI}$ 조작행위는 인간의 오류절편(error segment human, ESH)으로 나타내었다. 본 연구에서는 기기의 고유 특성과 인간의 조작행위를 하나 의 상호작용 단위로 간주하여, 상호작용 절편(interaction segment, IS)으로 정의하였다. 또한, 그 중에서 궁극적으로 직무상 인적오류로 발현되는 것을 오류절편(ES)으로 간주하 였으며, 디지털 기기의 사용 관련 오류절편(error segment interaction, ESI) 을 추가하였다.

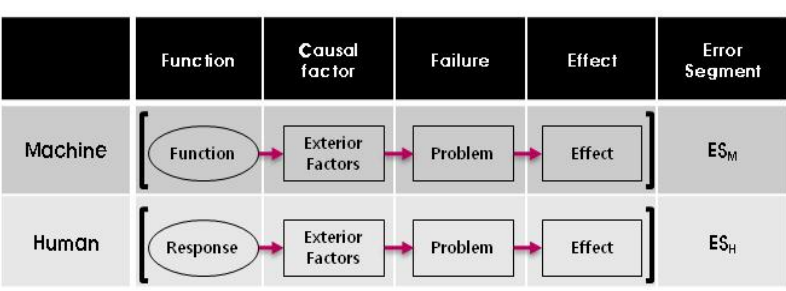

Figure 4. Error Segment(ES) (Lee, 2003)

\section{A Proposed Method for Human Error Hazard Identification in Digital Devices}

디지털 기기의 인적오류 위험성을 검출하기 위하여 제안한 기법의 절차는 기기의 사용자 조작 부위 및 기기를 이용한 예상직무의 세부요소를 도출한 후에, 인간공학적 평가 척도 들로써 인적오류의 발생 가능성을 판단하는 과정으로 요약 할 수 있다. 제안된 기법의 전체적 흐름은 Figure 5 와 같다.

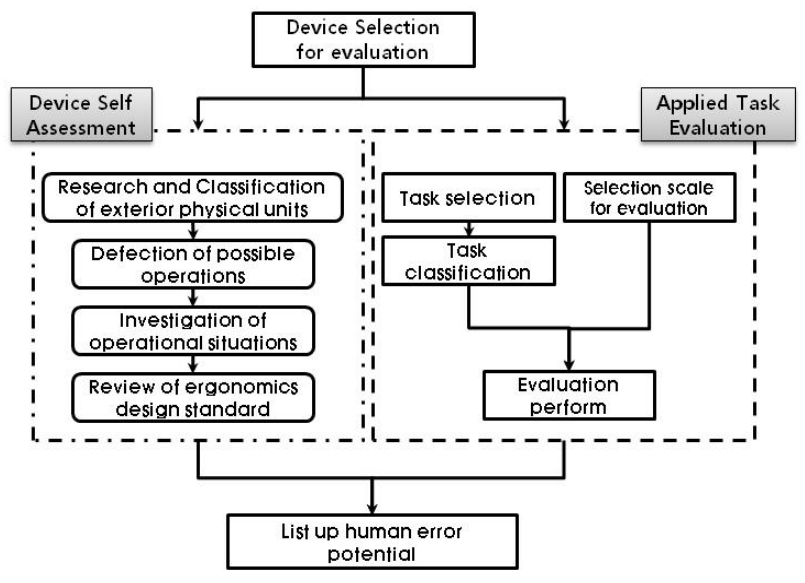

Figure 5. A flowdiagram of the proposed method

우선, 기기 자체 평가는 스마트모바일의 외부 조작 가능한 물리적 조작단위를 조사하여 망라한 후, 각 조작단위의 조작 방법 및 조작 상황에 따라 조작 전후의 기기상태 변화를 분 석하여 절편의 목록을 작성한다. 도출된 각 조작결과를 일관 성, 양립성, 그리고 가용성 등 인간공학적 설계 요건에 기초 하여 위배사항을 검출한다. 둘째로 직무 적용 평가는 대상 기기의 대표적인 직무를 선정한 후 직무의 단계를 세분하고, 각 단계별 절편들을 디자인, 작업환경, 시스템 안전 체계 등 선정된 평가 척도에 따라 평가한다. 기기 자체 평가의 경우, 스마트모바일의 물리적 조작단위는 주요 조작방법이지만 다 
양한 방식으로 개발이 가능한 소프트 컨트롤(soft control) 의 평가는 분석 수준 및 범위가 불확실하다. 또한, 직무 적용 평가의 경우, 기기 자체적으로 내포하고 있는 인적오류를 야 기하는 위험성을 모두 검출하기가 어렵기 때문에, 적정한 분 석 수준을 결정할 필요가 있다. 제안한 기법을 설명하기 위 하여 현재 상용화된 스마트폰의 분석결과를 다음 장에 예시 하였다.

\subsection{Device-based human error identification}

디지털 기기는 조작방법에 따라, 그리고 조작상태에 따라 같은 행위를 하더라도 결과가 달라질 수 있는 방대한 변수를 포함하고 있다. 따라서 기기 기반 평가에서는 Figure 6에서 보는 바와 같이 외부 물리적 조작단위를 조사하여 상호작용 절편을 정의하였고, 상황(mode)에 따른 결과를 기준으로 발생 가능한 오류절편의 유형을 분석하였다. 단 기기의 화면 상에 표시되는 앱(application)의 물리적 단위는 '아이콘'이 라는 단일 명칭의 요소로 분석하였다.

망라된 기기의 물리적 요소는 가능 조작방법 및 조작 전후 의 변화에 따라 절편을 구성하는데, 직접 직무상의 오류로 발현되지 않더라도 인간공학 기준을 위배할 경우에는 해당 상호작용 절편(IS)을 오류절편(ES)으로 규정하는 과정을 거친다.

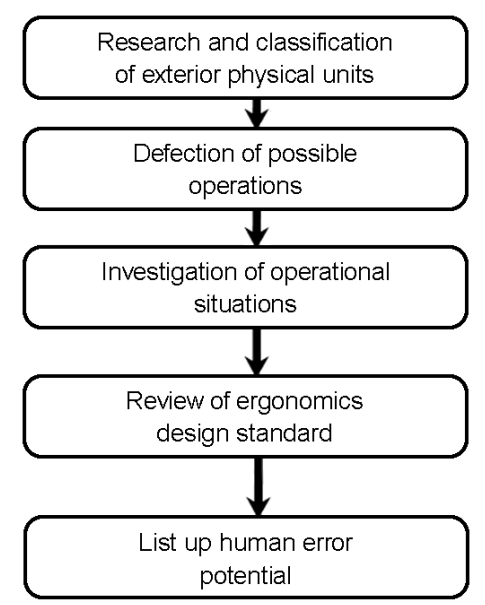

Figure 6. Flowchart of the device-based identification

\section{1) 기기의 외부 물리적 단위 분류/조사}

스마트모바일 기기의 경우, 스마트화의 결과로 버튼을 포 함하여 외부적으로 제공되는 물리적 조작단위 (physical unit) 의 수가 현저히 적다. 대신 하나의 조작단위에서 다양한 조 작이 가능하도록 설계되어 있다. 모든 물리적 조작단위에 대 하여 가능한 조작방법 (operational methods)을 조합하여
목록으로 만들고, 각각에 대한 결과를 항목별로 확인하는 과 정을 거친다.

Table 1은 전형적인 스마트모바일 기기의 외부 물리적 단위를 망라하여 나타낸 것이다. 분석을 위하여 외부 물리 적 단위의 기능적 명칭을 코드로 부여하였다. Yun et al. (2010)에 따르면 많은 사람들이 사용하는 스마트폰의 경우, 외부 물리적 조작단위의 수는 12 개에서 24 개 수준이며, 외 부의 조작 버튼뿐만 아니라 카메라, 이어폰 hole 등을 포 함해도 Table 1 의 범위를 크게 벗어나지 않을 것으로 판단 된다.

Table 1. Exterior physical units $\left(\mathrm{ES}_{\mathrm{M}}\right)$ of smart mobiles

\begin{tabular}{c|c|c|c}
\hline Code & $\begin{array}{c}\text { Exterior physical } \\
\text { units(ES }\end{array}$ & Code & $\begin{array}{c}\text { Exterior physical } \\
\text { units(ES }\end{array}$ \\
\hline $\mathrm{P}$ & Power button & BR & Battery removal \\
\hline $\mathrm{V}+$ & Volume up button & UR & USIM card removal \\
\hline $\mathrm{V}-$ & Volume down button & SR & SD card removal \\
\hline $\mathrm{H}$ & Home button & SE & Speaker(External) \\
\hline $\mathrm{T}$ & Track ball & SI & Speaker(Inner for calling) \\
\hline $\mathrm{B}$ & Return button & MH & Mike hole \\
\hline $\mathrm{L}$ & List button & $\mathrm{CL}(\mathrm{F})$ & Camera lens(Front) \\
\hline $\mathrm{M}$ & Menu button & $\mathrm{CL}(\mathrm{R})$ & Camera lens(Rear) \\
\hline $\mathrm{I}$ & Icon & $\mathrm{DA}$ & DMB antenna \\
\hline $\mathrm{D} / \mathrm{C}$ & Data/charging port & AS & Approach sensor \\
\hline $\mathrm{EH}$ & Earphone hole & $\mathrm{IS}$ & Illumination sensor \\
\hline $\mathrm{BC}$ & Battery cover & $\mathrm{CF}$ & Flash \\
\hline & & &
\end{tabular}

\section{2) 가능 조작 도출}

스마트모바일 기기는 같은 조작 장치라도 조작방법에 따 른 결과가 달라진다. 따라서 Table 2에서 보는 것과 같이, 단위 기기에 가능한 조작방법을 결합한 상호작용 절편을 도 출한다. 예를 들어, 전원버튼을 한 번 짧게 클릭할 경우 잠

Table 2. Operational methods of each unit(part)

\begin{tabular}{c|c}
\hline \multirow{2}{*}{ Code } & $\begin{array}{c}\text { Operation } \\
\text { Method }\end{array}$ \\
\hline \multirow{2}{*}{$\mathrm{P}$} & One click \\
\cline { 2 - 2 } & Long click \\
\hline \multirow{2}{*}{$\mathrm{V}+$} & One click \\
\cline { 2 - 2 } & Long click \\
\hline \multirow{2}{*}{$\mathrm{V}-$} & One click \\
\hline \multirow{2}{*}{$\mathrm{T}$} & Long click \\
\cline { 2 - 2 } & Rotation \\
\hline
\end{tabular}


Table 3. A result by operating method in each mode of smart mobile(part)

\begin{tabular}{|c|c|c|c|c|c|c|}
\hline Error Segments(ES) & \multicolumn{6}{|c|}{ Interaction Segments(IS) } \\
\hline \multirow{2}{*}{ Code } & \multirow{2}{*}{$\begin{array}{l}\text { Operation } \\
\text { method }\end{array}$} & \multicolumn{5}{|c|}{ Operation mode } \\
\hline & & No option(Vertical) & Manner mode & Horizontal mode & Multi task & Lock \\
\hline \multirow{2}{*}{$\mathrm{P}$} & One click & \multicolumn{5}{|c|}{ Screen on/off } \\
\hline & Long click & \multicolumn{5}{|c|}{ Pup-up window for option } \\
\hline \multirow{2}{*}{$\mathrm{V}+$} & One click & $\begin{array}{l}\text { Volume up } \\
\text { by stages }\end{array}$ & $\begin{array}{l}\text { Manner mode cancel } \\
\text { and volume up } \\
\text { by stages }\end{array}$ & \multirow{2}{*}{$\begin{array}{c}\text { Volume up by stages } \\
\text { (space compatibility violation) } \\
\text { Operation intention: down }\end{array}$} & $\begin{array}{l}\text { Volume up } \\
\text { by stages }\end{array}$ & None \\
\hline & Long click & $\begin{array}{l}\text { Volume up } \\
\text { rapidly }\end{array}$ & $\begin{array}{l}\text { Manner mode cancel } \\
\text { and volume up } \\
\text { rapidly }\end{array}$ & & $\begin{array}{l}\text { Volume up } \\
\text { rapidly }\end{array}$ & None \\
\hline \multirow{2}{*}{$\mathrm{V}-$} & One click & $\begin{array}{l}\text { Volume down } \\
\text { by stages } \\
\rightarrow \text { manner mode }\end{array}$ & Vibration & \multirow{2}{*}{$\begin{array}{c}\text { Volume down by stages } \\
\text { (space compatibility violation) } \\
\text { Operation intention: up }\end{array}$} & $\begin{array}{l}\text { Volume down } \\
\text { by stages } \\
\rightarrow \text { manner mode }\end{array}$ & None \\
\hline & Long click & $\begin{array}{l}\text { Volume down } \\
\text { rapidly } \\
\rightarrow \text { manner mode }\end{array}$ & Vibration & & $\begin{array}{l}\text { Volume down } \\
\text { rapidly } \\
\rightarrow \text { manner mode }\end{array}$ & None \\
\hline
\end{tabular}

시 화면을 보이지 않게 할 수 있지만, 길게 클릭할 경우 기 기 전체의 전원을 끌 수 있는 전원 조작 메뉴가 표시된다. 그 밖에도 개발자가 의도하였던 정상적인 조작방법과 달리, 복수 조작, 충격, 분해, 파괴 등 의도하지 않은 조작행위를 통한 비정상 조작방법을 별도로 구분하여 그에 따른 기기 상 태의 변화 및 영향을 분석하였다. 본 논문에서는 정상 조작 의 범위 내에서 분석한 결과를 중심으로 제안한 기법을 설 명하였다.

\section{3) 조작 전후 상태 변화 조사}

앞서 언급한 바와 같이 각 상황에 따라 외부 물리적 조작 단위를 조작한 결과가 달라질 수 있으므로, 가능한 모든 상 황요소를 추가로 고려한다. 현재 가용한 스마트폰을 예로 들 어 각 모드 별로 분석한 결과는 Table 3 과 같다. 일반상황과 비교하여 조작결과가 달라질 수 있는 상황을 잠김, 진동모드, 가로방향, 텍스트 입력, 일반 프로그램 실행, 미디어 프로그 램 실행 등 6 가지로 구분할 때, 각각의 결과가 달라진다는 것을 알 수 있다. '볼륨 상 버튼'의 세로방향 모드에서는 누 름 (click) 시 볼륨이 커지는 결과가 나타나 사용자의 예상과 부합한다. 하지만 Figure 7 과 같이 가로방향 모드에서는 왼 쪽방향이 증가를 나타내는 오른쪽(증가)으로 표시된다.

반대로 오른쪽 버튼(볼륨 하 버튼)을 누를 경우 표시는 왼 쪽(감소)으로 나타난다. 이는 조작방향의 양립성 요건을 위 배하므로 사용자에게 혼란을 일으키는 인적오류 가능성이 매우 큰 오류절편이다.

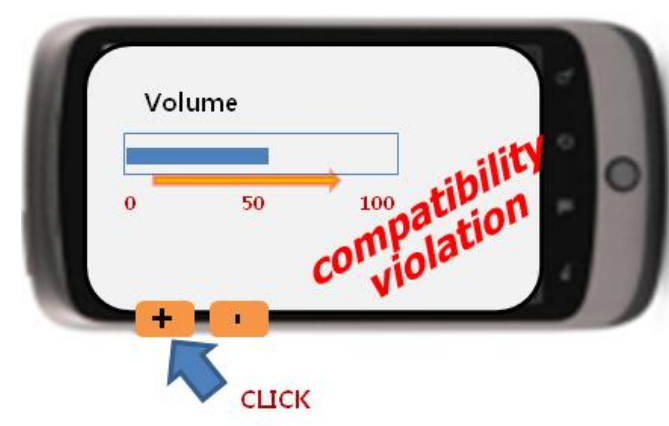

Figure 7. A case against to the compatibility criteria

4) 설계의도 및 인간공학 원칙 위배사항 검출

디지털 기기의 설계단계에서 인간공학적 원칙을 위반함으 로써, 사용과정에서 발생 가능한 다양한 유형의 오류 위험성 이 존재한다. 스마트폰의 경우, Table 2 의 분석결과를 바탕 으로 인적오류 가능성을 의미하는 오류절편을 검출하였다. 각 상황(mode)별로 조작에 따른 결과의 일관성, 양립성, 가 용성 등을 검토하여 위험성을 조사한 결과, '조작 및 표시방 향의 불일치', '조작결과의 일관성 부족', '진행 프로그램의 표 시부족', '화면 lock 기능 부재', '기기 설정의 표시 부족' 등 유형별로 인적오류 위험성을 검출할 수 있음을 알 수 있다.

\subsection{Task-based human error identification}

직무 적용 평가는 기기를 사용하는 대표적인 직무형태를 기준으로 인적오류 가능성을 검출하는 단계이다. 현재 원전 
내에서는 무선통신을 이용한 스마트모바일을 직무에 사용하 고 있지 않기 때문에, 스마트모바일을 적용할 수 있는 가상 의 직무를 선정하여 직무과정을 분석하였다.

원전 실무자들의 면담조사 결과, 스마트모바일 사용이 가 능한 직무는 현장 운전원과 $\mathrm{MCR}$ 운전원 간의 의사소통 매 개체로서의 기능이 가장 유력하다. 예를 들어, 업무를 지시 받아 관련 기기를 촬영하고 상태를 평가하여 결과를 전송하 는 직무에 스마트모바일을 적용하는 것이다. Table 4는 해당 직무의 일부분으로 스마트모바일로 현장 상태를 사진 촬영 하여 $\mathrm{MCR}$ 로 전송하는 과정을 대상으로 직무 적용 평가를 수행한 결과를 예시한 것이다. 현재 스마트모바일의 가용한 기본 프로그램을 활용하였고, 분해된 수행단계별로 사용되는 조작단위 및 각 조작단위별 가능한 조작방법을 운전단계, 조 작단위, 조작방법으로 나누어 Table 4 와 같이 목록으로 제 시하였다.

Table 4. Detailed steps of a generic task selected for an example

\begin{tabular}{|c|c|c|c|}
\hline Task & Operation step & Used units & $\begin{array}{c}\text { Operation } \\
\text { method }\end{array}$ \\
\hline \multirow{3}{*}{ Ready } & Power on & Power button & Click \\
\hline & Unlock & Lock button & Drag \\
\hline & Program running & Program & Click \\
\hline \multirow{2}{*}{ Shoot } & Shooting mode on & Camera & Click \\
\hline & Shoot & Shooting button & Click \\
\hline \multirow{7}{*}{ Transmission } & \multirow{2}{*}{$\begin{array}{l}\text { Target selection } \\
\text { (MCR, support } \\
\text { department etc) }\end{array}$} & $\begin{array}{l}\text { Number input } \\
\text { window }\end{array}$ & Click \\
\hline & & Number button & Click \\
\hline & \multirow[b]{3}{*}{ Input the content } & Text input window & Click \\
\hline & & Text button & Click \\
\hline & & $\begin{array}{l}\text { Setting button } \\
\text { (English/Korean, } \\
\text { symbol etc) }\end{array}$ & Click \\
\hline & Transmit & Send button & Click \\
\hline & $\begin{array}{l}\text { Check the } \\
\text { transmission }\end{array}$ & Confirm button & Click \\
\hline
\end{tabular}

물리적 단위와 가능한 조작의 조합으로 도출된 상호작용 절편의 오류 가능성을 평가하기 위하여, 스마트폰의 사례에 적용한 인간공학 기준 항목을 Table 5 와 같이 도출하였다.

사용자의 교육 수준, 시력, 연령, 성별, 및 손가락 크기 등 의 사용자 특성과 온도, 습도, 조도, 소음 등의 작업환경 요 소, 디지털 기기의 조작상태, 인간공학 및 시스템 안전 측면 에서의 설계 요건 등 많은 척도가 평가에 적용 가능하나, 원 전 직무에 우선하여 척도를 선정하였다. 목록으로 도출된 절 편에 적용할 때 설계 또는 시스템의 특성상 현실적으로 효용
이 있는 척도들을 선별적으로 적용할 수 있다.

Table 5. Evaluation criteria based on tasks using smart mobile

\begin{tabular}{l|l}
\hline Evaluation item & Scales \\
\hline \multirow{3}{*}{ Ergonomics design } & Compatibility \\
& Consistency \\
& Availability \\
\hline \multirow{4}{*}{ System security } & Feedback \\
& Pool proof \\
& Fail safe \\
& Alarm \\
& Recovery \\
\hline \multirow{3}{*}{ Design } & Awareness \\
& Difference \\
\hline \multirow{2}{*}{ Work environment } & Portability \\
\hline \multirow{2}{*}{ etc } & Wireless network \\
& Noise \\
\hline
\end{tabular}

본 연구에서 선정된 평가 척도는 인터페이스 설계를 위하 여 조작 및 표시의 일치, 공간 인식 등의 양립성, 조작에 따 른 결과의 일관성, 설정이나 시스템 부하 등의 표시로 인한 사용의 지속 가능성 등을 검토하는 항목들로 구성하고 있다. 또한, 스마트모바일의 사용시 사용자 실수나 기기 실패로부 터의 안전성 확보 여부, 경보나 피드백의 적절성을 검토하는 항목들로 구성한다. 디자인 측면에서는 조작버튼(아이콘 포 함)의 모호함이나 다른 버튼과의 차별성 부족으로 발생할 수 있는 오류 가능성을 평가하며, 현장에서 기기 조작 시 휴 대나 조작이 용이한지 평가한다. 스마트모바일은 원거리 통 신 및 조작이 용이할 때 더욱 업무효율성이 증가되는 기기이 므로 무선네트워크의 지원 여부를 상시 확인하고, 소음으로 인한 통신 방해가 없는지를 작업환경 측면에서 검토한다. 실 수나 착오 이후 직전 화면으로의 복귀 가능성, 다중업무 확 인 등의 평가가 이루어지도록 하였다. 마지막으로 해당 직무 의 실행에서 교육훈련에 의한 인적오류 방지의 가능성을 평 가하여 요건화한다.

Table 6 과 같이 앞서 선정한 직무의 각 수행단계 별로 평 가기준에 의거한 위험성을 도출하여 발생 가능한 오류목록 을 도출하였다. 준비단계에서 해당 프로그램을 실행하는 경 우, 디자인 문제로 인하여 인지율(친숙성)이 떨어져 해당 실 행 프로그램을 찾는데 시간이 지연될 가능성이 존재한다. 또 한 다른 실행 프로그램과의 차별성이 떨어져 피드백 기능이 결여되고, 이는 원치 않는 프로그램을 실행시키는 결과를 낳 는다. 이와 같이 같은 조작단위를 같은 방법으로 조작을 하 더라도 그 상황적 관련 변수들로 인하여 다른 유형의 오류 
Table 6. A result table after applying human factors criteria

\begin{tabular}{|c|c|c|c|c|c|c|c|c|c|c|c|c|c|c|c|c|c|c|c|}
\hline \multirow{2}{*}{ Task } & \multirow{2}{*}{$\begin{array}{c}\text { The } \\
\text { operation } \\
\text { step }\end{array}$} & \multirow{2}{*}{$\begin{array}{l}\text { The } \\
\text { used } \\
\text { unit }\end{array}$} & \multirow{2}{*}{$\begin{array}{c}\text { The } \\
\text { operation } \\
\text { method }\end{array}$} & \multicolumn{3}{|c|}{ Ergonomics design } & \multicolumn{5}{|c|}{ System security } & \multicolumn{3}{|c|}{ Design } & \multicolumn{2}{|c|}{$\begin{array}{c}\text { Work } \\
\text { environment }\end{array}$} & \multicolumn{2}{|c|}{ etc } & \multirow{2}{*}{ Result } \\
\hline & & & & $\begin{array}{c}\text { Compati- } \\
\text { bility }\end{array}$ & $\begin{array}{c}\text { Consist- } \\
\text { ency }\end{array}$ & $\begin{array}{c}\text { Availa- } \\
\text { bility }\end{array}$ & $\begin{array}{l}\text { Fail } \\
\text { safe }\end{array}$ & $\begin{array}{l}\text { Pool } \\
\text { proof }\end{array}$ & $\begin{array}{c}\text { Feed- } \\
\text { back }\end{array}$ & Alarm & Recovery & $\begin{array}{c}\text { Aware- } \\
\text { ness }\end{array}$ & $\begin{array}{c}\text { Differ- } \\
\text { ence }\end{array}$ & $\begin{array}{l}\text { Porta- } \\
\text { bility }\end{array}$ & $\begin{array}{l}\text { Wireless } \\
\text { network }\end{array}$ & Noise & Training & $\begin{array}{c}\text { Multi- } \\
\text { tasking }\end{array}$ & \\
\hline \multirow{6}{*}{ Ready } & \multirow{2}{*}{$\begin{array}{l}\text { Power } \\
\text { on }\end{array}$} & \multirow{2}{*}{$\begin{array}{l}\text { Power } \\
\text { button }\end{array}$} & \multirow{2}{*}{ Click } & & & & & & & & & $\mathrm{O}$ & & & & & $\mathrm{O}$ & & Failure to turn on device \\
\hline & & & & & & & & & & & & $\mathrm{O}$ & & & & & & & Failure to turn on device \\
\hline & \multirow{2}{*}{ Unlock } & \multirow{2}{*}{$\begin{array}{c}\text { Lock } \\
\text { button }\end{array}$} & \multirow{2}{*}{ Drag } & & & & & & & & & & & & & & $\mathrm{o}$ & & Work delay \\
\hline & & & & $\mathrm{o}$ & & & & & & & & $\mathrm{O}$ & & & & & & & Work delay \\
\hline & \multirow{2}{*}{$\begin{array}{l}\text { Program } \\
\text { running }\end{array}$} & \multirow{2}{*}{ Program } & \multirow{2}{*}{ Click } & & & & & & & & & $\mathrm{O}$ & & & & & & & Work delay \\
\hline & & & & & & & & & $\mathrm{o}$ & & & & $\mathrm{o}$ & & & & & & Run unintended program \\
\hline \multirow[t]{2}{*}{ Shoot } & $\begin{array}{l}\text { Shooting } \\
\text { mode on }\end{array}$ & Camera & Click & & & & & & & & & & & & & & $\mathrm{O}$ & & $\begin{array}{l}\text { Failure to run program } \\
\text { Unintentional setting } \\
\text { change } \\
\text { Run unintended program }\end{array}$ \\
\hline & Shoot & $\begin{array}{c}\begin{array}{c}\text { Shooting } \\
\text { button }\end{array} \\
\end{array}$ & Click & $\mathrm{O}$ & & & & & & & & $\mathrm{O}$ & & & & & & & $\begin{array}{l}\text { Unintentional setting } \\
\text { change } \\
\text { Illusion }\end{array}$ \\
\hline \multirow{9}{*}{$\begin{array}{c}\text { Trans- } \\
\text { mission }\end{array}$} & \multirow{3}{*}{$\begin{array}{c}\text { Target } \\
\text { selection } \\
\text { (MCR, } \\
\text { support } \\
\text { department } \\
\text { etc) }\end{array}$} & $\begin{array}{c}\text { Number } \\
\text { input } \\
\text { window }\end{array}$ & Click & & & & & & & & & $\mathrm{O}$ & & & & & $\mathrm{o}$ & & $\begin{array}{l}\begin{array}{l}\text { Failure to point on the } \\
\text { window }\end{array} \\
\end{array}$ \\
\hline & & \multirow{2}{*}{$\begin{array}{c}\text { Number } \\
\text { button }\end{array}$} & \multirow{2}{*}{ Click } & & & & & $\mathrm{O}$ & $\mathrm{o}$ & & $\mathrm{o}$ & & & & & & & & $\begin{array}{l}\text { Simple error such as } \\
\text { wrong writing }\end{array}$ \\
\hline & & & & & & & & $\mathrm{O}$ & $\mathrm{O}$ & & $\mathrm{O}$ & & & & & & & & $\begin{array}{l}\text { Run unintended } \\
\text { program }\end{array}$ \\
\hline & \multirow{4}{*}{$\begin{array}{c}\text { Input } \\
\text { the content }\end{array}$} & $\begin{array}{c}\text { Text } \\
\text { input } \\
\text { window }\end{array}$ & Click & & & & & & & & & $\mathrm{O}$ & & & & & $\mathrm{O}$ & & $\begin{array}{l}\text { Failure to point on the } \\
\text { window }\end{array}$ \\
\hline & & \multirow{2}{*}{$\begin{array}{c}\text { Text } \\
\text { button }\end{array}$} & \multirow[t]{2}{*}{ Click } & & & & & $\mathrm{O}$ & $\mathrm{o}$ & & $\mathrm{O}$ & & & & & & & & $\begin{array}{l}\text { Simple error such as } \\
\text { wrong writing }\end{array}$ \\
\hline & & & & & & & & $\mathrm{O}$ & $\mathrm{O}$ & & $\mathrm{O}$ & & & & & & & & Run unintended program \\
\hline & & \begin{tabular}{|c|}
$\begin{array}{c}\text { Setting } \\
\text { button } \\
\text { (English/ } \\
\text { Korean, } \\
\text { symbol } \\
\text { etc) }\end{array}$ \\
\end{tabular} & Click & & & & & & & & & $\mathrm{o}$ & & & & & $\mathrm{o}$ & & $\begin{array}{l}\text { Conversion failure to the } \\
\text { symbol button }\end{array}$ \\
\hline & Transmit & $\begin{array}{c}\text { Send } \\
\text { button }\end{array}$ & Click & & & & & & & & & & & & & & & & Failure to send message \\
\hline & $\begin{array}{l}\text { Check the } \\
\text { transmission }\end{array}$ & \begin{tabular}{c|} 
Confirm \\
button
\end{tabular} & Click & & & & & & & & & & & & & & & & \\
\hline
\end{tabular}

가 나타나는 것을 예상할 수 있다.

\section{An Application Scheme to Interface Design for Nuclear Power Plants}

스마트모바일의 원전 사용에 대한 전자기적 안전성을 확 보한다면 다양한 휴대용 첨단 기기들이 원전에 도입될 것이 다. 그러나 빠르게 변화하는 새로운 기술을 사후경험을 기반 으로 인적오류 위험성을 평가한다면, 예상하지 못한 위험성 에 적절히 대처하기 어렵다. 그러므로, 본 논문에서는 스마 트모바일을 비롯한 첨단 기기들의 원전 도입시 디지털 기기 의 설계과정에서 인적오류 위험성 평가를 병행하는 기본 체 계로 Figure 8과 같은 절차를 제안하였다.
우선, 설계목적에 적합한 기기를 선정하고 프로그램 설계 가 착수되는 초기단계에서 인적오류 위험성 분석을 병행하 도록 한다. 기기 자체적 평가는 기기의 물리적 조작단위를 도출하고, 각 조작 상황과 방법에 따른 결과를 검토한 후, 선 별한 인간공학적 설계 요건에 따라 평가한다. 기기 자체적 평가는 새로운 기기를 도입할 경우 실행하며, 기기 부품의 신뢰성 평가를 통하여 유지보수 기간 동안 정기 점검을 수행 한다. 직무 적용 평가는 일정 범위의 샘플 직무를 선정한 후 대상 직무를 상호작용의 단위로 분해한다. 이 때 직무기반 평가 척도로 각 절편의 위험성을 평가한다. 직무 적용 평가 는 새로운 기기나 새로운 프로그램을 도입할 때뿐만 아니라 해당 프로그램을 개정할 때마다 평가하며, 일정 주기로 프로 그램 검정을 수행한다.

기법의 적용에 따른 결과로써 오류절편 목록을 작성한 후 위험성을 도출하면, 인적오류 위험성에 대해 설계과정에서 


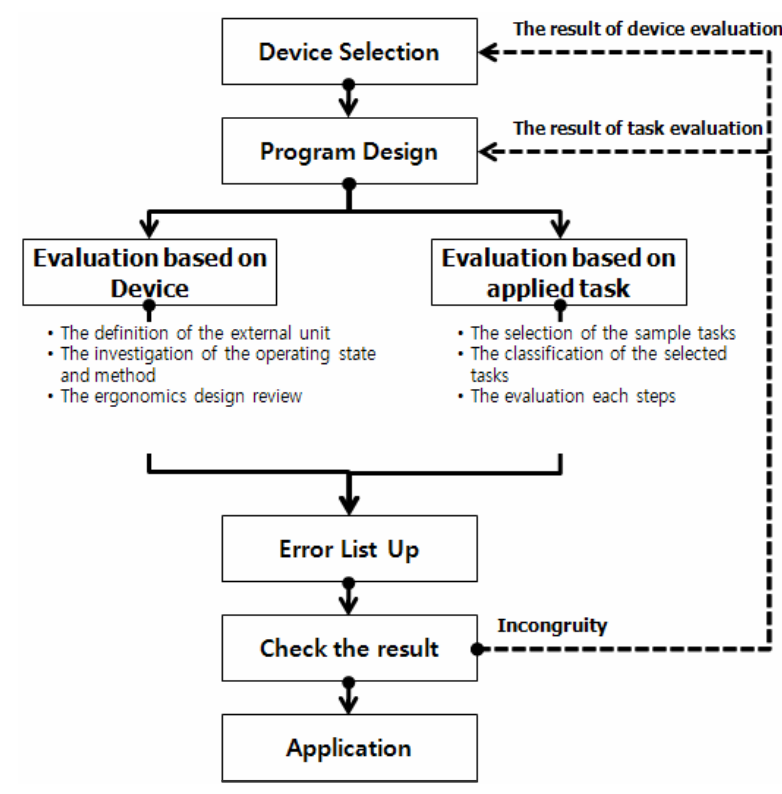

Figure 8. An applicaition scheme for the NPP design

검토가 충실할 수 있으며, 오류 위험성을 고려한 기기 및 인 터페이스의 설계가 가능하다. 만약 관리적 대비 이외에 해결 되지 않는 위험성이 있을 경우, 교육 및 훈련 요건으로 대신 한다. 전체 평가 체계는 인간공학자가 설계자를 지원하는 동 시공학적 설계방식이다.

제안된 기법과 설계지원 업무 체계를 적용하여 도출된 스 마트폰의 인적오류 위험성을 Table 7 과 같이 제시하였다. 기기 자체적 평가결과에 따른 위험성으로는 조작과 표시방 향의 불일치, 같은 조작방법에 따른 결과의 일관성 결여, 필 요 정보의 표시부족 등 설계 단계에서의 인간공학적 문제점 을 도출할 수 있었다. 스마트모바일을 적용한 직무를 평가한 결과, 설계상에서 발생되는 낮은 인지율, 사용자의 단순 실 수로 인한 잘못된 접근, 익숙하지 않은 인터페이스에 따른 혼란 야기, 무선네트워크 환경 문제 등 경험상으로는 파악하 기 어려운 위험성을 도출할 수 있음을 알 수 있다.

Table 7. Lists of plausible errors in smart mobile tasks

\begin{tabular}{c|l}
\hline Phase & \multicolumn{1}{|c}{ Human error hazard } \\
\hline \multirow{4}{*}{$\begin{array}{c}\text { Evaluation } \\
\text { based on } \\
\text { device }\end{array}$} & $\begin{array}{l}\text { Inconsistency between the operation and display } \\
\text { direction in the horizontal mode }\end{array}$ \\
\cline { 2 - 2 } & $\begin{array}{l}\text { The lack of operation consistency on main button } \\
\text { click(several program stop and several program } \\
\text { running etc) }\end{array}$ \\
\cline { 2 - 2 } & The lack of display on the running programs \\
\cline { 2 - 2 } & The absence of lock function in the operating display \\
\cline { 2 - 2 } & The lack of display of the setting \\
\hline
\end{tabular}

Table 7. Lists of plausible errors in smart mobile tasks (Continued)

\begin{tabular}{|c|c|}
\hline Phase & Human error hazard \\
\hline \multirow{8}{*}{$\begin{array}{l}\text { Evaluation } \\
\text { based on } \\
\text { applied task }\end{array}$} & $\begin{array}{l}\text { It's difficult to find the operation device(button) } \\
\text { because of insufficiency cognition }\end{array}$ \\
\hline & The operator makes run unintended program \\
\hline & The operator makes run the unnecessary program \\
\hline & The simple error such as wrong writing \\
\hline & $\begin{array}{l}\text { The interpretation and comprehension error due to the } \\
\text { difficult or unfamiliar sentences }\end{array}$ \\
\hline & $\begin{array}{l}\text { The failure recovery to the previous step since the } \\
\text { path deviation }\end{array}$ \\
\hline & The conversion failure to the symbol button \\
\hline & The alarm failure(wireless network environment etc) \\
\hline
\end{tabular}

기기의 모든 조작에 따른 결과 조사와 프로그램을 실행시 켜 촬영 및 전송하는 단순한 직무에서도 다수의 오류유형을 도출할 수 있었다. 직무기반 오류유형은 대부분 교육훈련을 통하여 숙련이 가능하지만 설계단계에서부터 이와 같은 오 류 가능성을 고려한다면 인적오류를 방지하고 나아가 직무 수행도를 개선할 수 있을 것이다.

\section{Conclusions}

본 연구에서는 첨단 디지털 기기의 원전 도입에 대비하기 위하여 기기 설계 및 적용에 따른 인적오류 위험성을 도출하 는 기법을 제시하였다. 현재 원전에서는 안전성 검증 부족으 로 도입이 보류되고 있지만, 추후 도입 가능성이 높다고 판 단되는 스마트모바일의 설계 및 현장 직무 적용 시 발생 가 능한 인적오류의 위험성 항목을 도출함으로써, 예방 설계를 지원하고자 하였다. 기기 자체의 특성에 따른 조작 오류를 포함하는 기기 오류 위험성과 직무과정에서 유도되는 인적 오류 위험성을 검출하는 과정이 제안된 기법의 핵심이다. 예 상 원전 직무에 스마트모바일을 적용하였을 때를 가정하여 제안된 기법으로 평가한 결과, 스마트모바일의 외부 물리적 단위뿐만 아니라 인터페이스 설계상 다수의 오류절편이 있 으며, 단순히 촬영 및 전송하는 직무라도 다양한 위험성이 존재함을 확인할 수 있었다.

제안된 기법으로 도출된 인적오류 위험성의 검증을 위하 여 인지적 오류상태를 검출하는 뇌파(EEG) 기반의 평가 기 법을 개발하여 실험적으로 기법의 검증을 시도하고 있다 $(\mathrm{Oh}$ \& Lee 2011). 또한 이미 발생한 원전의 사건사례에 스마트 모바일을 포함한 디지털 기기를 사용할 경우를 가정하여, 직 
무 시나리오상의 인적오류 가능성에 대한 실험적 검증을 수 행하고 있다. 현재 수행중인 기법의 검증결과를 바탕으로 스마트모바일 뿐만 아니라 디지털 기기의 원전 도입에 적용 하여 원전의 안전성을 확립하는 기반으로 활용할 수 있을 것으로 판단한다. 이러한 절차를 실무용 도구로 개발하면 현 장의 실무를 지원하는 요소기술로 적극 활용할 수 있을 것이

다(Lee et al., 2011).

다만, 디지털 기기에 대한 인간공학 연구가 다양하게 수행 되고 있으나, 최신 기기 기반의 서비스 차원에서의 인적오류 위험성 연구는 미흡한 실정이다(Lee, 2011). 복합적인 위 험성을 내포하고 있는 대형 또는 공공 시설에서 스마트모바 일과 같은 최신 기술을 적극 활용하기 위해서는 인적오류 위 험성을 체계적으로 검출하여 안전성 위협에 대처해야 할 것 이다.

\section{References}

Jung K. T. and Lee, Y. H., A basic study on human error proneness in computerized work environment, Journal of the Ergonomics Society of Korea, Vol.19, No.1, pp.1-9, 2000.

Lee, Y. H., Facilitating HRA through the Input from HSI Design, 2-nd OECD/NEA Workshop on Building the New HRA, 2002.

Lee, Y. H., A State-of-the-Art Report on the Current Human Error Studies: What and How to Cope with, Journal of the Ergonomics Society of Korea, Vol.30, No.1, pp.1-8, 2011.

Lee, Y. H., A Scrutinized analysis method of the Human Error Potential due to the Introduction of New Digital Devices to Nuclear Power Plants, HCII-2011, Florida, USA, 2011.

Lee, Y. H., Jang, T. I. and Lim, H. K, A Modification of Human Error Analysis Technique for Designing Man-Machine Interface in Nuclear Power Plants, Journal of the Ergonomics Society of Korea, Vol.22, No.1, pp.31-42, 2003.

Lee, Y. H, Jang, T. I., Lee Y., Oh, Kang, S. H., Y. J. and Yun, J. H., Research Activities and Techniques for the Prevention of Human Errors during the Operation of Nuclear Power Plants, Journal of the Ergonomics Society of Korea, Vol.30, No.1, pp.75-86, 2011.

Oh, Y. J. and Lee, Y. H., A Study on the Operator's Erroneous Responses to the New Human Interface of a Digital Device to be Introduced to
Nuclear Power Plants, HCII-2011, Florida, USA, 2011.

Yun, J. H. and Lee, Y. H., Development of a Human Error Evaluation Method for Introducing Smart Mobile to Nuclear Power Plants, Proc. ESK 2011 Fall Conf., 2011.

Yun, J. H., Oh, Y. J. and Lee, Y. H., Development of Risk Analysis Method for Extremely-Low Frequency Human Error of Digital Devices, Proc. ESK 2010 Fall Conf., 2010.

\section{Author listings}

Yong Hee Lee: yhlee@kaeri.re.kr

Highest degree: Ms, Department of Industrial Engineering, Seoul National University

Position title: Section Head, Division of I\&C and Human Factors, Korea Atomic Energy Research Institute(KAERI)

Areas of interest: Human Error, HMI, Cognitive System Engineering

Jong Hun Yun: jhyun@kict.re.kr

Highest degree: Ms, Department of Safety Engineering, Chungbuk National University

Position title: Safety Engineer, Administration Department, Korea Institute of Construction Technology(KICT)

Areas of interest: Industrial Safety, Human Error, System Safety, WMSDs

Yonghee Lee: yonghee@kaeri.re.kr

Highest degree: $\mathrm{PhD}$, Department of Industrial System Engineering, Dong-A University

Position title: Senior Researcher, Division of I\&C and Human Factors, Korea Atomic Energy Research Institute (KAERI)

Areas of interest: Organization \& Management, Human Error, Job Stress

Date Received : 2011-12-13

Date Revised :2012-01-13

Date Accepted : 2012-01-13 